\title{
Clinical features and mortality-related factors of extensive burns among young adults: the Kunshan disaster experience
}

\author{
Ying-Zi Huang ${ }^{1}$, Guo-Zhong Lu ${ }^{2}$, Hong-Sheng Zhao ${ }^{3}$, Li-Jun Liu ${ }^{4}$, Jun Jin ${ }^{5}$, Yun-Fu $\mathrm{Wu}^{6}, \mathrm{Jian} \mathrm{Wu}^{7}$, \\ Fu-Li Zhao ${ }^{8}$, Ning Liu ${ }^{9}$, Wen-Ming Liu ${ }^{10}$, Long Liu ${ }^{11}$, Tuan-Jie Zhu ${ }^{12}$, Er-Zhen Chen ${ }^{13}$, Qin Gu ${ }^{14}$, \\ Hong-Wei $\mathrm{Ye}^{15}$, Xiu-Ming $\mathrm{Xi}^{16}$, Bin $\mathrm{Du}^{17}$, Yang $\mathrm{Yi}^{18}$, Hai-Bo Qiu ${ }^{19}$
}

${ }^{1}$ Department of Critical Care Medicine, Zhongda Hospital, School of Medicine, Southeast University, Nanjing, China; ${ }^{2}$ Department of Burn, Burn Intensive Care Unit, Wuxi Third People's Hospital, Wuxi, China; ${ }^{3}$ Department of Critical Care Medicine, Affiliated Hospital of Nantong University, Nantong, China; ${ }^{4}$ Department of Emergency and Critical Care Medicine, the Second Affiliated Hospital of Soochow University, Suzhou, China; ${ }^{5}$ Department of Critical Care Medicine, the First Affiliated Hospital of Soochow University, Suzhou, China; ${ }^{6}$ Department of Critical Care Medicine, Suzhou Municipal Hospital, Suzhou, China; ${ }^{7}$ Department of Critical Care Medicine, North district of Suzhou Municipal Hospital, Nanjing Medical University, Suzhou, China; ${ }^{8}$ Department of Critical Care Medicine, Suzhou Municipal Hospital, Suzhou, China; ${ }^{9}$ Department of Critical Care Medicine, The Third Affiliated Hospital of Suzhow University, Changzhou 1st People's Hospital, Changzhou, China; ${ }^{10}$ Department of Critical Care Medicine, Changzhou 2nd People's Hospital, Nanjing Medical University, Changzhou, China; ${ }^{11}$ Department of Critical Care Medicine, Kunshan People's Hospital, Suzhou, China; ${ }^{12}$ Department of Critical Care Medicine, Su Zhu Kowloon Hosipital, Shanghai Jiaotong University Medical School, Shanghai, China; ${ }^{13}$ Department of Critical Care Medicine, Ruijin Hospital, Shanghai Jiaotong University School of Medicine, Shanghai, China; ${ }^{14}$ Department of Critical Care Medicine, Nanjing Drum Tower Hospital, Nanjing, China; ${ }^{15}$ Department of Critical Care Medicine, Changshu No.1 People's Hospital, Suzhou, China; ${ }^{16}$ Department of Critical Care Medicine, Fuxing Hospital, Capital Medical University, Beijing, China;

${ }^{17}$ Medical ICU, Peking Union Medical College Hospital, Peking Union Medical College \& Chinese Academy of Medical Sciences, Beijing, China; ${ }^{18}$ Department of Critical Care Medicine, Zhongda Hospital, School of Medicine, Southeast University, Nanjing, China; ${ }^{19}$ Department of Critical Care Medicine, Zhongda Hospital, School of Medicine, Southeast University, Nanjing, China

Contributions: (I) Conception and design: YZ Huang, HB Qiu, B Du; (II) Administrative support: GZ Lu, XM Xi; (III) Provision of study materials or patients: YZ Huang, HS Zhao, LJ Liu, J Jin, YF Wu, J Wu, FL Zhao, N Liu, WM Liu, L Liu, TJ Zhu, EZ Chen, Q Gu, HW Ye; (IV) Collection and assembly of data: YZ Huang, Y Yi, HS Zhao; (V) Data analysis and interpretation: YZ Huang, Y Yi, B Du; (VI) Manuscript writing: All authors; (VII) Final approval of manuscript: All authors.

Correspondence to: Hai-Bo Qiu. Department of Critical Care Medicine, Zhongda Hospital, School of Medicine, Southeast University, 87 Dingjiaqiao Rd., Nanjing, China. Email: haiboq2000@163.com.

Background: The aim of the study was to identify the clinical features and the factors associated with burn induced mortality among young adults after exposure to indoor explosion and fire.

Methods: This is an observational study which included burn patients who were admitted to eighteen ICUs after a fire disaster. Epidemiologic and clinical characteristics, as well as therapy were recorded. The primary outcome was 90-day mortality. The mortality-related factors were also analyzed.

Results: There were 167 burn patients enrolled in the study, the median age was 38 years, $62(37.1 \%)$ patients died within 90 days. Seventy-one percent of patients had a burn size $\geq 90 \%$ TBSA, and $73.7 \%$ of patients had a full-thickness burn area above 50\% TBSA. The survivors had lower Baux scores, and received earlier escharectomy and autologous skin grafts. The 50\% mortality rates (LA50s) for burn size and fullthickness burn area were $95.8 \%$ and $88.6 \%$ TBSA, respectively. The multivariate analysis showed that fullthickness burn area over 50\% TBSA and residual burned surface area (RBSA)/TBSA at 28 days were strong predictors of mortality among burn patients (odds ratio 2.55 ; 95\% CI, 1.01 to $6.44, \mathrm{P}=0.047$; odds ratio 1.07; 95\% CI, 1.04 to $1.09, \mathrm{P}<0.001$ ). The ROC curve-based cut-off values of RBSA/TBSA at 28 days for predicting 90-day mortality were $62.5 \%$.

Conclusions: Burn size and full-thickness burn area were the main risk factors for poor outcome in patients with extensive burns. Earlier escharectomy and autologous skin grafts may improve outcomes.

Keywords: Extensive burns; mortality; escharectomy; autologous skin grafts; residual burned surface area 
Submitted Jan 04, 2020. Accepted for publication Jul 31, 2020.

doi: 10.21037/atm-20-288

View this article at: http://dx.doi.org/10.21037/atm-20-288

\section{Introduction}

Burn injuries are the most severe form of trauma, accounting for approximately 330,000 deaths per year worldwide (1). Burns are the fourth leading cause of death from unintentional injury in the United States and result in 1.4 million injuries each year (2). The survival rate is worse among those with extensive burns; the mortality rate was reported to reach as high as $97.8 \%$ in patients with a burn area over $70 \%$ total body surface area (TBSA) (3). Additionally, age, gender and accompanying inhalation injuries are associated with a high mortality rate.

In the last twenty years, advancements in fluid resuscitation, early closure of burn wounds, grafting techniques and materials, and nutritional support combined with life support systems have further improved the survival rate of patients experiencing extensive burn. In 1952, the $50 \%$ mortality rate (LA50) for burn area was 50\% TBSA in patients under 17 years, whereas in 1994, the LA50 for burn area was $98 \%$ TBSA in young people (4). Recently, the mortality rate of pediatric burn patients was found to be significantly increased above a threshold of $62 \%$ TBSA (2). Our study examined the outcomes of a flammable dust fire and explosion accident that was a disastrous, group accidental injury requiring special critical care and burn surgery services.

In the present study, we analyzed the prognosis of extensive burn patients who were in an explosion and burn accident that occurred on August 2, 2014, in Kunshan, China. Most of the patients had a burn size $\geq 90 \%$ TBSA (full-thickness burn area $\geq 80 \%$ TBSA), were generally young. Our aims were as follows: (I) to identify the clinical and epidemiologic characteristics of these patients with extensive burns, (II) to explore the associations of surgical procedures and use of life support systems with prognosis, and (III) to analyze the factors related to mortality in this cohort. We present the following article in accordance with the STROBE reporting checklist (available at http://dx.doi. org/10.21037/atm-20-288).

\section{Methods}

\section{Data collected}

On August 2, 2014, a flammable dust fire and explosion accident occurred in Kunshan, China. The Chinese government responded quickly to treat the wounded. This analysis included 167 burned patients. These 167 thermally injured patients were admitted to 18 ICUs and were resuscitated according to the Brooke formula ( $2 \mathrm{~mL} / \mathrm{kg} / \%$ TBSA), applying target endpoints of a mean arterial pressure greater than $60 \mathrm{mmHg}$ and a urinary output of $0.5-2.0 \mathrm{~mL} / \mathrm{kg} / \mathrm{h}$ to adhere to the hemodynamic targets defined for early goal-directed therapy (2). All patients received total burn wound debridements and escharotomies, and any remaining open wound areas were covered with allografts as soon as the initial resuscitation had been completed.

Smoke inhalation injury was suspected because most of the patients had experienced an injury in a closed space. The patients presented with clinical features including facial burns, carbonaceous sputum, soot in the nares, and burns of the head and neck (5).

Sepsis was defined as meeting three or more American Burn Association criteria for sepsis (6), along with a positive result from tissue or blood culture analysis. Diagnosed septic shock was defined according to the Surviving Sepsis Campaign 2012 definition (7). We followed the Berlin criteria for acute respiratory distress syndrome (ARDS) (8). Acute kidney injury (AKI) was defined according to the Kidney Disease Improving Global Outcomes (KDIGO) criteria (9). Acute gastrointestinal injury (AGI), were defined according to the European Society of Intensive Care Medicine (ESICM) Working Group (10).

The patients were divided into two groups, survivors and non-survivors, based on 90-day mortality. We collected data: age, sex, Acute Physiology and Chronic Health Evaluation (APACHE II) score, Sequential Organ Failure Assessment (SOFA) score, measured or estimated burn size (\% TBSA by Lund and Browder, Rule of Nines), Baux index (age + $\%$ TBSA) (11), Belgian Outcome in Burn Injury scores (including subscores ranging from 0 to 4 for $\%$ TBSA, from 0 to 3 for age, and subscores of either 0 or 3 for absence or presence of inhalation injury, respectively (12), date and time of first endotracheal intubation, tracheotomy, first escharectomy and autologous skin graft, residual burned surface area (RBSA/TBSA) at 28 and 60 days. We calculated the duration of mechanical ventilation, CRRT, vasopressor 
use, and enteral feeding. Moreover, LA50 and mortality were recorded through 90 days.

\section{Data management}

The data collection and analysis were coordinated by the 8.2 Kunshan Burn Clinical Investigation Group of China. The data were reviewed by a trained team of physicians and were entered in duplicate into a computerized database. The trial was conducted in accordance with the Declaration of Helsinki (as revised in 2013). The research ethics board at Zhongda Hospital, Southeast University, approved the study design (2014ZDSYLL121.1), and informed consent was given by each patient or their next of kin.

\section{Statistical analysis}

Data are presented as continuous or categorical variables. Continuous data were evaluated for normality using the Kolmogorov-Smirnov test and summarized as either the mean \pm standard deviation $(\mathrm{SD})$ or the median with interquartile range. For categorical variables, the frequency and percentage of patients in each category were calculated. Comparisons between 'survivors' and 'non-survivors' were performed using Student's $t$-test, Mann-Whitney U test, Chi-square test or Fisher's exact test as appropriate. Twoway analysis of variance (ANOVA) was used to compare SOFA scores and fluid resuscitation, blood plasma, albumincontaining fluid, crystalloid fluid and urine volumes between the survivor and non-survivor groups and at different time points. Student-Newman-Keuls post hoc test was used when indicated. LA50 was derived from probit analysis (both probit and logit models), and generalized $U$ statistics were calculated to compare the areas under the ROC curves. Cox regression analysis was performed to evaluate the possible risk factors (including age, sex, APACHE II score, TBSA, Baux scores and Revised Baux scores, etc.) influencing 90 -day mortality. A P value $<0.05$ was considered statistically significant, and all statistical analyses were performed using SPSS 13.0 (SPSS Inc., Chicago, IL, USA).

\section{Results}

\section{Patient characteristics and main outcomes}

In total, 167 patients enrolled in our study, 62 of whom (37.1\%) died within 90 days; the 28- and 60-day mortality rates were $13.8 \%$ and $29.9 \%$, respectively. There were 96 men $(57.5 \%)$ and 71 women (42.5\%). The median age was 38 years. Additionally, $71.3 \%$ of the patients had a burn size of $\geq 90 \%$ TBSA, and $73.7 \%$ of the patients had a fullthickness burn area over $50 \%$ TBSA. The median fullthickness burn area was $82 \%$ TBSA. Among patients with severe burn injury (full-thickness burn area $\geq 50 \%$ TBSA), the LA50 for full-thickness burn area was $88.63 \%$ TBSA (95\% CI, $75.7 \%$ to $120.2 \%$ TBSA). Among all 167 patients, 91\% experienced inhalation injury, and the median Baux index and Belgian Outcome in Burn Injury were 145 and 7, respectively. Greater burn area and depth were associated with a higher mortality rate (Figure 1).

Compared to the non-survivors, those who survived had a lower APACHE II score $(\mathrm{P}<0.001)$ and Baux index $(\mathrm{P}<0.001)$. The duration of septic shock was significantly shorter in the survivors than in the non-survivors $(\mathrm{P}<0.001)$. The non-survivors had larger burn areas and full-thickness burn areas than the survivors $(\mathrm{P}<0.001)$ (Table 1). Mortality appeared to have a positive relationship with burn surface area and full-thickness burn area (Figure 2). Forty-five patients $(72.6 \%)$ died of septic shock, and ten patients (16.1\%) died of traumatic shock (Table 1).

\section{Surgical treatment}

One hundred and fifty patients $(89.8 \%)$ received relaxing incisions to relieve tension. The timing of the first escharectomy and autologous skin graft differed significantly between the survivors and non-survivors $(\mathrm{P}=0.001$ and $\mathrm{P}=0.008$, respectively). Furthermore, 26 patients received early tangential excision, 17 of whom $(65.5 \%)$ died, and 115 patients received early escharectomy, 87 of whom $(68.8 \%)$ survived $(\mathrm{P}<0.001)$. The 28 - and 60 -day RBSA/ TBSA were significantly smaller in the survivors than in the non-survivors $(\mathrm{P}<0.001)$ (Table 2).

\section{Life support care}

Tracheotomy and mechanical ventilation were commonly performed on burn patients. Vasopressors were administered to 123 patients (73.7\%). Compared with the survivors, the non-survivors more frequently received CRRT $(\mathrm{P}<0.001)$ and had a longer duration of CRRT within 28 days $(\mathrm{P}=0.033)$ and 90 days $(\mathrm{P}=0.001)$, as well as fewer mechanical ventilation-free days within 28 days $(\mathrm{P}<0.001)$. The crystalloid and albumin-containing fluid volumes administered within the first 24 hours were greater in the non-survivors than in the survivors $(\mathrm{P}=0.001$ and 


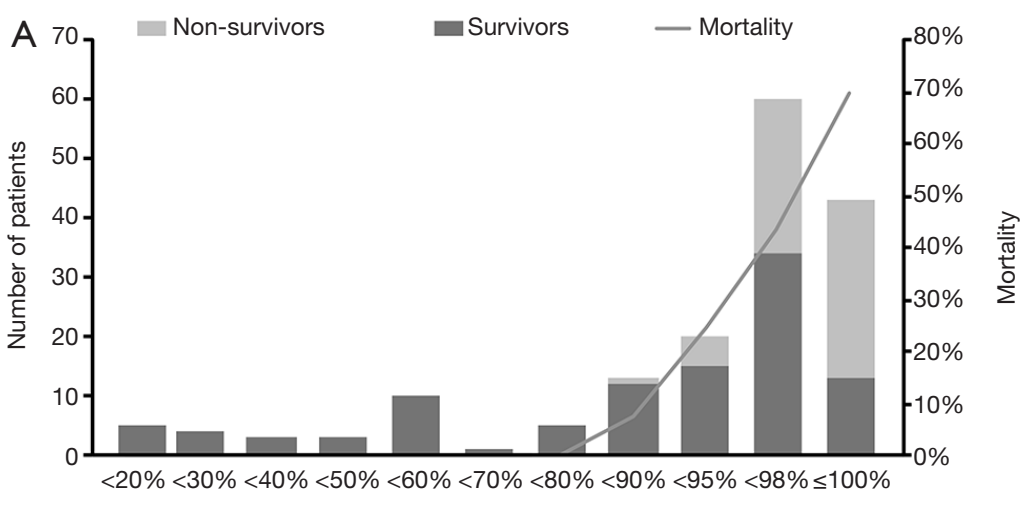

TBSA

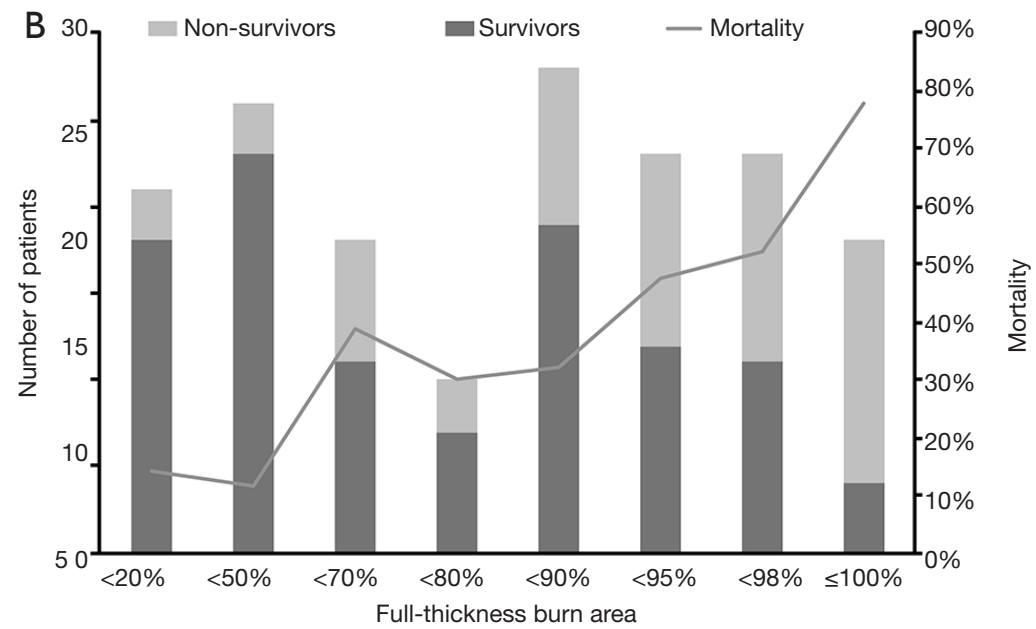

Figure 1 The relationship between burn area, thickness and mortality.

Table 1 Characteristics, combined injury at baseline, and complications of the burn patients

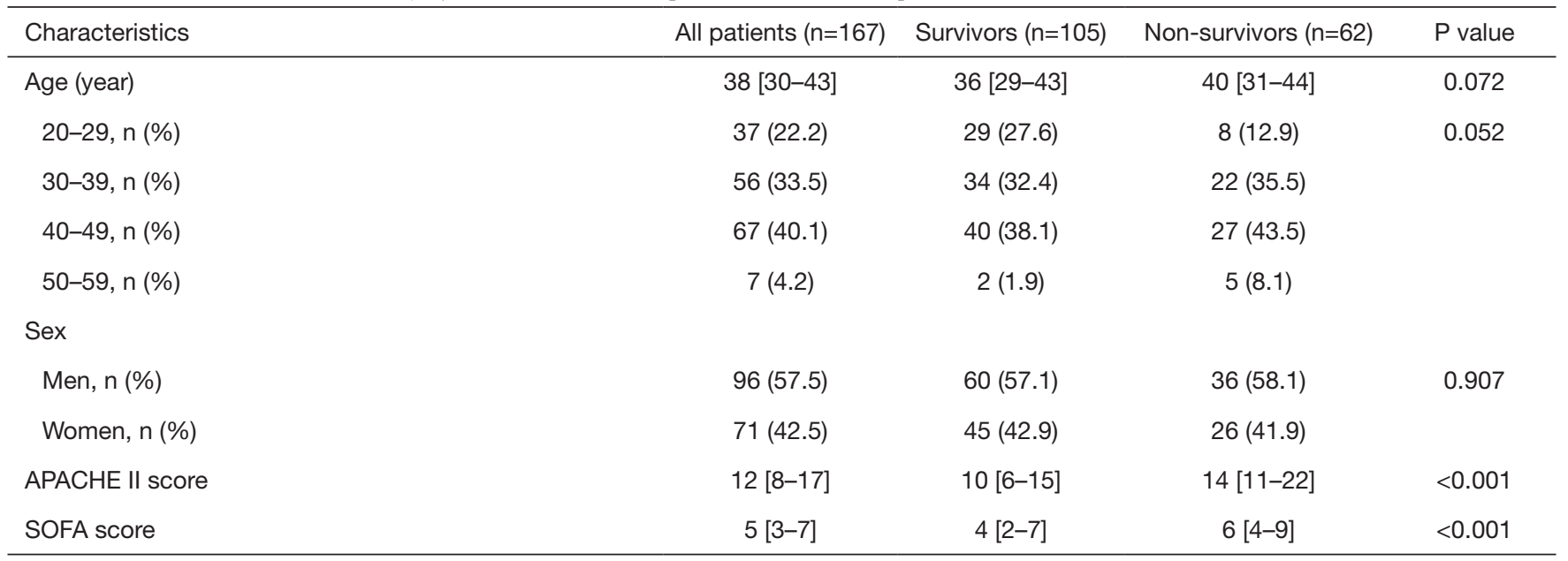

Table 1 (continued) 
Table 1 (continued)

\begin{tabular}{|c|c|c|c|c|}
\hline Characteristics & All patients $(n=167)$ & Survivors $(n=105)$ & Non-survivors $(n=62)$ & $P$ value \\
\hline$<50, \mathrm{n}(\%)$ & $15(9.0)$ & $15(14.3)$ & $0(0.0)$ & $<0.001$ \\
\hline $50-69, \mathrm{n}(\%)$ & $11(6.6)$ & $11(10.5)$ & $0(0.0)$ & \\
\hline $70-89, \mathrm{n}(\%)$ & $18(10.8)$ & $17(16.2)$ & $1(1.6)$ & \\
\hline 95-97, n (\%) & $60(36.0)$ & $34(32.4)$ & $26(41.9)$ & \\
\hline $98-100, n(\%)$ & $43(25.7)$ & $13(12.4)$ & $30(48.4)$ & \\
\hline Full-thickness burns area-total area (\%) & 82 [40-94] & $70[25-90]$ & $91[80-97]$ & $<0.001$ \\
\hline$<50, \mathrm{n}(\%)$ & $47(28.1)$ & $41(39)$ & $6(9.7)$ & $<0.001$ \\
\hline 90-94, n (\%) & $23(13.8)$ & $12(11.4)$ & $11(19.4)$ & \\
\hline 95-97, n (\%) & $23(13.8)$ & $11(10.5)$ & $12(19.4)$ & \\
\hline $98-100, \mathrm{n}(\%)$ & $18(10.8)$ & $4(3.8)$ & $14(22.6)$ & \\
\hline Inhalation injury, n (\%) & $152(91.0)$ & $91(86.7)$ & $61(98.4)$ & 0.010 \\
\hline Baux scores & $128[118-138]$ & $123[102-133]$ & $136[128-141]$ & 0.000 \\
\hline Revised Baux score & $145[134-155]$ & $140[119-151]$ & $153[145-158]$ & $<0.001$ \\
\hline Severity of burn injury (Belgian Outcome in Burn Injury) & $7[7-7]$ & $7[5-7]$ & $7[7-7]$ & $<0.001$ \\
\hline AKI stage III & $88(52.7)$ & $31(29.5)$ & $57(91.9)$ & \\
\hline AGI, n (\%) & $113(67.7)$ & $65(61.9)$ & $48(77.4)$ & 0.038 \\
\hline \multicolumn{5}{|l|}{ Combined injury } \\
\hline Traumatic brain injury, $\mathrm{n}(\%)$ & $10(6.0)$ & $2(1.9)$ & $8(12.9)$ & 0.011 \\
\hline Traumatic thoracic injury, n (\%) & $25(15.0)$ & $16(15.2)$ & $9(14.5)$ & 0.899 \\
\hline Traumatic abdomen injury, $\mathrm{n}(\%)$ & $5(3.0)$ & $2(1.9)$ & $3(4.8)$ & 0.545 \\
\hline Traumatic limb fractures, $\mathrm{n}(\%)$ & $21(12.6)$ & $13(12.4)$ & $8(12.9)$ & 0.922 \\
\hline Duration of traumatic hemorrhagic shock (day) & $2[1-3](n=158)$ & $2[1-3](n=105)$ & $2[1-3](n=53)$ & 0.756 \\
\hline Time of initiation of sepsis (day) & $4[3-5](n=138)$ & $4[3-5](n=85)$ & $4[3-5](n=53)$ & 0.960 \\
\hline Time of initiation of septic shock (day) & $5[4-9](n=116)$ & $5[4-10](n=63)$ & $5[4-7](n=53)$ & 0.603 \\
\hline Duration of septic shock (day) & $11.3 \pm 12.4(n=116)$ & $7.6 \pm 11.2(n=63)$ & $18.6 \pm 11.5(n=53)$ & $<0.001$ \\
\hline
\end{tabular}

AGI, acute gastrointestinal injury; AKI, acute kidney injury; APACHE, acute physiology and chronic health evaluation; ARDS, acute respiratory distress syndrome; RBSA, residual burned surface area; SOFA, sequential organ failure assessment; TBSA, total body surface area. 


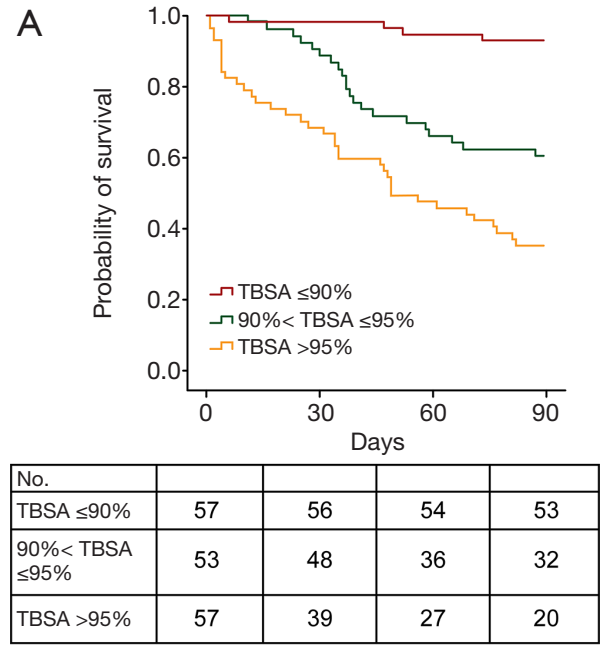

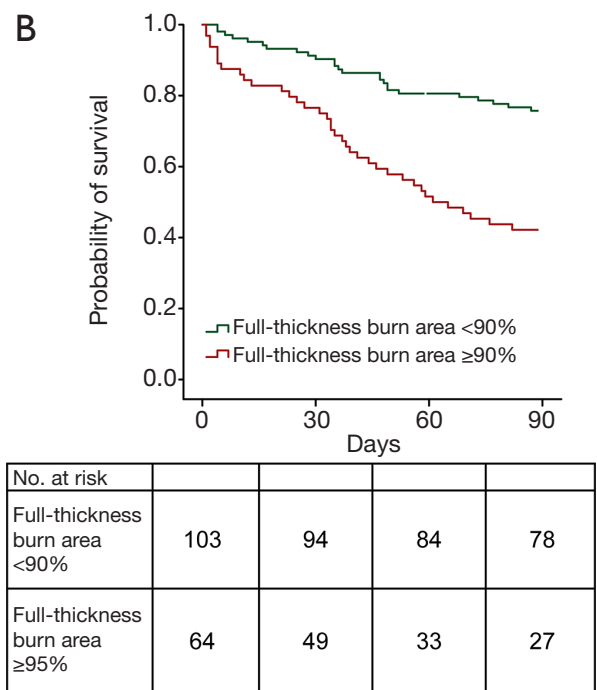

Figure 2 The relationship of burn surface area (A) and fullthickness burn area (B) with survival.

$\mathrm{P}=0.009$, respectively). Enteral and parenteral feeding were initiated early, at a median of 2 and 3 days after injury, respectively, and post-pyloric tubes were placed in 84 patients $(50 \%)$.

\section{Risk of mortality analysis}

A full-thickness burn area over 50\% TBSA was a strong predictor of mortality, with a hazard ratio of mortality 2.55 times greater than a full-thickness burn area below that threshold (95\% CI, 1.01 to 6.44; $\mathrm{P}=0.047$ ). The RBSA/total area at 28 days (hazard ratio, 1.07; 95\% CI, 1.04 to 1.09 , $\mathrm{P}<0.001)$ was another important risk factor that influenced 90-day mortality (Table 3). The ROC curve analysis of RBSA/total area at 28 days and at 60 days as a predictor of 90 -day mortality produced cut-off values of $62.5 \%$ and $24 \%$, respectively (Figure 3).

\section{Discussion}

In this study, we described the epidemiological and clinical characteristics of a cohort of 167 burn patients in 18 hospitals who were injured in a flammable dust fire and explosion accident. Most of our sample was young (median age, 38 years) and had severe burns (median burn size, 95\% TBSA), but the mortality rate of our cohort appeared lower $(37.1 \%)$ than that reported in other studies $(13,14)$. Furthermore, we analyzed the factors related to mortality and found that full-thickness burn area over $50 \%$ and 28-day RBSA/TBSA were indicators of 90-day mortality in severe and major burn patients.

The surgical principles of early excision of devitalized tissue and prompt wound closure determine the primary treatment of burns. Wound excision and closure can be started as early as the initial assessment and can be performed during ongoing resuscitation (15). Muller et al. found a reduced mortality with early excision (within 72 hours) (4). The 28- and 60-day RBSAs were smaller in survivors than in non-survivors. Previous studies as well as our study showed that severely burned patients benefitted from early eschar excision and grafting (16-19). Time of first autologous skin grafting is important. Unfortunately, some severe burn patients received escharectomy and autologous skin grafting later because of the instability caused by severe shock or the unavailability of skin autografts in the initial stage of burn treatment.

Most patients in this study only experienced traumatic shock in the 1-3 days after injury, but the ensuing wound healing process and improvement in conditions such as septic shock, ARDS, AKI and AGI influenced patient outcomes. Therefore, full support of the circulatory, respiratory, renal and nutritional systems is essential not only to treat wounds but also to improve patient prognosis. In our study, many advanced therapeutic principles and measures, such as early goal-directed fluid resuscitation therapy, early enteral nutrition (EN), early CRRT, lung-protective ventilation, invasive monitoring of hemodynamics, and monitoring of multiple organ function, were applied (11). Compared with the survivors, the nonsurvivors had a longer duration of mechanical ventilation and CRRT within 28 days of the injury. The treatment of 
Table 2 Surgical treatment of burn patients

\begin{tabular}{|c|c|c|c|c|}
\hline Surgical treatment & All patients $(n=167)$ & Survivors $(n=105)$ & Non-survivors $(\mathrm{n}=62)$ & $P$ value \\
\hline Time of first tension-relaxing incision (hours) & $12[12-12](n=150)$ & $12[12-12](n=91)$ & $12[12-12](n=59)$ & 0.110 \\
\hline Times of tension-relaxing incision (days) & $1[1-1](n=150)$ & $1[1-1](n=91)$ & $1[1-1](n=59)$ & 0.098 \\
\hline Eschar excision, n (\%) & $141(84.4)$ & $96(89.7)$ & $45(75.0)$ & 0.012 \\
\hline Times of eschar excision, $n, 28$ days & $2[1-3](n=141)$ & $2[1-3](n=96)$ & $2.5(0.25-3)(n=45)$ & 0.705 \\
\hline \multicolumn{5}{|l|}{ Method of early eschar excision } \\
\hline Early tangential excision, $\mathrm{n}(\%)$ & $26(17.4)$ & $9(34.5)$ & $17(65.5)$ & $<0.001$ \\
\hline Early escharectomy, n (\%) & $115(82.6)$ & $87(68.8)$ & $28(31.2)$ & \\
\hline Times of autologous skin grafting, $n, 28$ days & $3[1-3](n=139)$ & $3[2-4](n=96)$ & $3[2-4](n=43)$ & 0.923 \\
\hline \multicolumn{5}{|l|}{ RBSA/TBSA } \\
\hline RBSA/TBSA (\%), 28 days & $60[41-77](n=148)$ & $51[25-70](n=105)$ & $77[67-84](n=43)$ & $<0.001$ \\
\hline RBSA/TBSA (\%), 60 days & $20[3-43](n=118)$ & 15 [2-35] (n=105) & $48[37-59](n=13)$ & $<0.001$ \\
\hline RBSA/TBSA (\%), 90 days & $0[0-5](n=105)$ & $0[0-5](n=105)$ & $-(n=0)$ & - \\
\hline
\end{tabular}

RBSA, residual burned surface area; TBSA, total body surface area.

Table 3 Multivariate cox regression analysis of factors influencing 90-day mortality

\begin{tabular}{|c|c|c|c|c|}
\hline \multirow{2}{*}{$\begin{array}{l}\text { Variable } \\
\text { RBSA/total area, 28-day }\end{array}$} & \multicolumn{4}{|c|}{ Hazard ratio estimates } \\
\hline & $\frac{\text { Hazard ratio }}{1.07}$ & 1.04 & 1.09 & $\begin{array}{l}P \text { value } \\
<0.001\end{array}$ \\
\hline Full-thickness burn area $\geq 50 \%$ TBSA & 2.55 & 1.01 & 6.44 & 0.047 \\
\hline Age & 1.03 & 0.99 & 1.07 & 0.120 \\
\hline Severity of burn injury & 1.35 & 0.52 & 3.52 & 0.545 \\
\hline Baux index & 0.99 & 0.95 & 1.03 & 0.639 \\
\hline Burn area $\geq 90 \%$ TBSA & 2.39 & 0.29 & 19.87 & 0.419 \\
\hline
\end{tabular}

APACHE, acute physiology and chronic health evaluation; RBSA, residual burned surface area; SOFA, sequential organ failure assessment; TBSA, total body surface area.

patients with extensive burns remains a major challenge, and these advances in burn care are very important improvements.

The goal of fluid resuscitation is to maintain adequate tissue perfusion after burn injury (20). Findings for the fluid resuscitation volume and sepsis incidence are conflicting (21). Specifically, in this study, half of the calculated fluids required are administered within the first 8 hours, and the remaining half are provided over the next 16 hours. In our study, crystalloid fluids, especially lactated ringer's solution, were the most commonly utilized resuscitation fluid, and the patients received substantial 


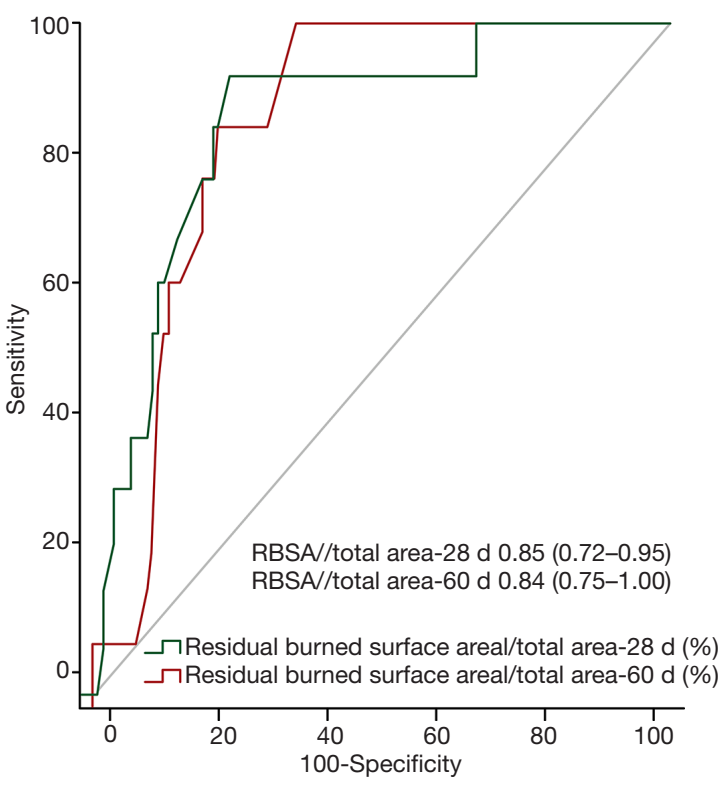

Figure 3 The ROC curve analysis of RBSA/total area at 28 days and at 60 days.

amounts of albumin-containing fluid and blood plasma in the first 24 hours after trauma. However, all patients were needed to transferred to the center hospitals for subsequent therapy, relatively small volumes of fluids, especially blood plasma and albumin-containing fluids were given within the first 8 hours. The efficacy of early fluid resuscitation with hydroxyethyl starch in burn injury continues to be debated $(22,23)$, and it was therefore rarely used in our study.

As extensive burns generate a pronounced hypermetabolic state, the resulting increases in energy and protein requirements should be addressed. Early EN plays a key role in the overall management of burn patients. EN has been recommended to be initiated within the first 24-48 hours after injury and to be increased to the goal rate in the subsequent 48-72 hours (24). In our study, we attempted to initiate enteral feeding as soon as possible; $50 \%$ of the inpatients received a post-pyloric feeding tube. However, only $74.7 \%$ of the patients received enteral feeding within 3 days. The survivors began enteral feeding within 2 days of trauma, which was earlier than the non-survivors. However, in our study, total daily caloric intake in the first week was apparently insufficient (25). AGI, stress ulcers, restricted enteral feeding, unstable circulation, and restricted parenteral feeding were the primary reasons for the insufficiency in total daily calorie intake.

Burn size and depth are major risk factors for poor outcome. Our population was composed of severe burn patients (median full-thickness burn area of $82 \%$ TBSA), but the mortality of this cohort appeared to be lower (37.1\%) than that observed in previous studies. LA50 is strongly associated with the mortality rate. In the 1930s, the LA50 was estimated to be $30 \%$ TBSA (13). Taylor et al. reported that the overall LA50 after burn injury had increased to $70 \%$ TBSA (15). In our burn patients, the LA50 was 95.8\% TBSA. Other studies have addressed the possible age- and gender-dependent effects on burn injury-related mortality (26). The mortality rates of very young ( $<2$ years) and very old ( $>60$ years) burn patients continue to be high. The LA50 for a person greater than 60 years old remained $30 \%$. Our population was composed of severe burn patients with a median age of 38 years and with few underlying diseases, and both younger age and the presence of few underlying diseases are strongly related to reduced mortality rates.

Predicting survival and outcomes has always been an important goal in the treatment of thermally injured patients. In this study, the Cox regression analysis showed that full-thickness burn area over $50 \%$ and RBSA/total area at 28 days were independent risk factors for 90-day mortality. We ROC curve analysis of the RBSA/total area at 28 and 60 days to predict 90 -day mortality, and the resulting cut-off values were $62.5 \%$ and $24 \%$, respectively.

There are several potential limitations of this study related to our dataset. First, the study was a clinical observational study, not a randomized controlled trial. Second, the few burn patients who had burn size $<40 \%$ TBSA may have influenced the statistical results. Third, there were lots of factors could impact survival, we may miss something. Our findings identify specific areas requiring further investigation.

\section{Conclusions}

Burn size and full-thickness burn area were the main risk factors for poor outcome in patients with extensive burns, but could be salvaged by intensive care. Earlier escharectomy and autologous skin grafts may improve outcomes after extensive burns. However, organ protection, antiinfection, rehabilitation and psychotherapy are quite important for lifesaving.

\section{Acknowledgments}

Funding: This work was supported by the National 
Natural Science Foundations of China (81571874); the Natural Science Foundation of Jiangsu Province of China (BK2014134); and Jiangsu Provincial Key Medical Discipline (ZDXKA2016025).

\section{Footnote}

Reporting Checklist: The authors have completed the STROBE reporting checklist. Available at http://dx.doi. org/10.21037/atm-20-288

Data Sharing Statement: Available at http://dx.doi. org/10.21037/atm-20-288

Peer Review File: Available at http://dx.doi.org/10.21037/ atm-20-288

Conflicts of Interest: All authors have completed the ICMJE uniform disclosure form (available at http://dx.doi. org/10.21037/atm-20-288). All authors have no conflicts of interest to declare.

Ethical Statement: The authors are accountable for all aspects of the work in ensuring that questions related to the accuracy or integrity of any part of the work are appropriately investigated and resolved. The trial was conducted in accordance with the Declaration of Helsinki (as revised in 2013). The study protocol was approved by the Ethics Committee of Zhongda Hospital, School of Medicine, Southeast University (2014ZDSYLL121.1), and informed consent was given by each patient or their next of kin.

Open Access Statement: This is an Open Access article distributed in accordance with the Creative Commons Attribution-NonCommercial-NoDerivs 4.0 International License (CC BY-NC-ND 4.0), which permits the noncommercial replication and distribution of the article with the strict proviso that no changes or edits are made and the original work is properly cited (including links to both the formal publication through the relevant DOI and the license). See: https://creativecommons.org/licenses/by-nc-nd/4.0/.

\section{References}

1. Peden $M, M c G e e K$, Sharma G. The injury chart book: a graphical overview of the global burden of injuries. The World Health Organization, 2002.

2. Kraft R, Herndon DN, Al-Mousawi AM, et al. Burn size and survival probability in paediatric patients in modern burn care: a prospective observational cohort study. Lancet 2012;379:1013-21.

3. Iqbal T, Saaiq M, Ali Z. Epidemiology and outcome of burns: early experience at the country's first national burns centre. Burns 2013;39:358-62.

4. Muller MJ, Herndon DN. The challenge of burns. Lancet 1994;343:216-20.

5. Rech TH, Boniatti MM, Franke CA. Inhalation injury after exposure to indoor fire and smoke: The Brazilian disaster experience. Burns 2016;42:884-90.

6. Greenhalgh DG, Saffle JR, Holmes JH, et al. American burn association consensus conference to define sepsis and infection in burns. J Burn Care Res 2007;28:776-90.

7. Dellinger RP, Levy MM, Rhodes A, et al. Surviving sepsis campaign: International guidelines for management of severe sepsis and septic shock: 2012. Crit Care Med 2013;41:580-637.

8. Ranieri VM, Rubenfeld GD, Thompson BT, et al. Acute respiratory distress syndrome: the Berlin definition. JAMA 2012;307:2526-33.

9. Fliser D, Laville M, Covic A, et al. A European renal best practice (ERBP) position statement on the kidney disease improving global outcomes (KDIGO) clinical practice guidelines on acute kidney injury: part 1: definitions, conservative management and contrast-induced nephropathy. Nephrol Dial Transplant 2012;27:4263-72.

10. Blaser A, Malbrain M, Starkopf J, et al. Gastrointestinal function in intensive care patients: terminology, definitions and management. Recommendations of the ESICM working group on abdominal problems. Intensive Care Med 2012;38:384-94.

11. Lundy JB, Chung KK, Pamplin JC, et al. Update on the critical care management of severe burns. J Intensive Care Med 2016;31:499-510.

12. Belgian Outcome in Burn Injury Study Group: Development and validation of a model for prediction of mortality in patients with acute burn injury. Br J Surg 2009;96:111-7.

13. Rose JK, Herndon DN. Advances in the treatment of burn patients. Burns 1997;23:S19-26.

14. Liu Y, Wu P, Ho JK, et al. Epidemiology of bus fires in mainland China from 2006 to 2015. Burns 2018;44:995-9.

15. Taylor S, Jeng J, Saffle JR, et al. Redefining the outcomes to resources ratio for burn patient triage in a mass casualty. J Burn Care Res 2014;35:41-5.

16. Wang Y, Tang HT, Xia ZF, et al. Factors affecting survival in adult patients with massive burns. Burns 2010;36:57-64. 
17. Barret JP, Herndon DN. Effects of burn wound excision on bacterial colonization and invasion. Plast Reconstr Surg 2003;111:744-50.

18. Herndon DN, Barrow RE, Rutan RL, et al. A comparison of conservative versus early excision. Ann Surg 1989;209:547-52.

19. Quinby WC, Burke JF, Bondoc CC, et al. Primary excision and immediate wound closure. Intensive Care Med 1981;7:71-6.

20. He H, Long Y, Zhou X, et al. Oxygen-flow-pressure targets for resuscitation in critical hemodynamic therapy. Shock 2018;49:15-23.

21. Paratz JD, Stockton K, Paratz ED, et al. Burn resuscitation--hourly urine output versus alternative endpoints: a systematic review. Shock 2014;42:295-306.

22. Béchir M, Puhan MA, Fasshauer M, et al. Early fluid resuscitation with hydroxyethyl starch 130/0.4 (6\%) in

Cite this article as: Huang YZ, Lu GZ, Zhao HS, Liu LJ, Jin J, Wu YF, Wu J, Zhao FL, Liu N, Liu WM, Liu L, Zhu TJ, Chen EZ, Gu Q, Ye HW, Xi XM, Du B, Yi Y, Qiu HB. Clinical features and mortality-related factors of extensive burns among young adults: the Kunshan disaster experience. Ann Transl Med 2020;8(17):1053. doi: 10.21037/atm-20-288 severe burn injury: a randomized, controlled, double-blind clinical trial. Crit Care 2013;17:R299.

23. Perner A, Haase N, Guttormsen AB, et al. Hydroxyethyl starch 130/0.42 versus ringer's acetate in severe sepsis. N Engl J Med 2012;367:124-34.

24. McClave SA, Martindale RG, Vanek VW, et al. Guidelines for the provision and assessment of nutrition support therapy in the adult critically ill patient: society of critical care medicine (SCCM) and American society for parenteral and enteral nutrition (A.S.P.E.N.). J Parenter Enteral Nutr 2009;33:277-316.

25. Guo F, Zhou H, Wu J, et al. A prospective observation on nutrition support in adult patients with severe burns. Br J Nutr 2019;121:974-81.

26. Palmieri TL, Molitor F, Chan G, et al. Long-term functional outcomes in the elderly after burn injury. J Burn Care Res 2012;33:497-503. 